\title{
ALUR KOMUNIKASI DI PERPUSTAKAAN PROKLAMATOR BUNG HATTA (PPBH) BUKITTINGGI
}

\author{
Oleh: Resty Jayanti Fakhlina
}

Tujuan penelitian dari studi deskriptif dengan pendekatan kualitatif ini adalah untuk menganalisis alur komunikasi di Perpustakaan Proklamator Bung Hatta (PPBH) Bukittinggi. Peneliti merupakan instrumen dalam penelitian ini. Teknik pengumpulan data yang digunakan adalah wawancara, observasi, dan studi pustaka. Hasil peneliti ini menunjukkan bahwa atasan dan staf di Perpustakaan Proklamator Bung Hatta (PPBH) Bukittinggi melakukan alur komunikasi dalam organisasi yang terdiri dari komunikasi ke bawah, komunikasi ke atas, komunikasi horizontal, komunikasi lintas saluran, dan komunikasi informal/selentingan/desas-desus berdasarkan faktor-faktor seperti proses aliran informasi, metode, media, format komunikasi, dan umpan balik. Kesimpulan dari penelitian ini adalah bahwa beberapa poin dari alur komunikasi yang terjadi pada pustakawan di Perpustakaan Proklamator Bung Hatta (PPBH) Bukittinggi masih belum sesuai dengan teori alur komunikasi dalam organisasi, terutama pada komunikasi ke bawah, komunikasi ke atas, dan komunikasi lintas saluran. Namun demikian pada poin komunikasi horizontal dan komunikasi informal/selentingan/desas-desus sudah sesuai dengan teori alur komunikasi organisasi.

Kata kunci: Komunikasi dalam Organisasi;Alur Komunikasi dalam Organisasi;Alur Komunikasi di Perpustakaan.

1) Balai Besar Pendidikan dan Pelatihan Kesejahteraan Sosial Yogyakarta

2) Fakultas Ilmu Sosial dan Politik, Universitas Gajah Mada Yogyakarta

\section{PENDAHULUAN}

Perpustakaan sebelumnya hanya mempunyai fungsi edukasi, fungsi penyimpanan, fungsi penelitian, fungsi informasi, dan fungsi kultural. Sebagai suatu lembaga, perpustakaan sekarang ini telah beradaptasi dengan perkembangan zaman yang terjadi di masyarakat, sehingga fungsi perpustakaan pun ikut berkembang dan bertambah dengan adanya fungsi publikasi, fungsi deposit, dan fungsi interpretasi.

Dengan bertambahnya fungsi perpustakaan, maka diperlukan kinerja organisasi yang baik. Dalam meningkatkan kinerja perpustakaan, diperlukan hubungan yang baik antar sesama sumber daya manusia yang ada di perpustakaan. Hubungan tersebut harus dipelihara mulai dari alur komunikasi atasan ke bawahan, alur komunikasi bawahan ke atasan, ataupun alur komunikasi antar orang-orang pada tingkatan yang sama, serta alur komunikasi lintas saluran di perpustakaan tersebut. Selain itu, hubungan tersebut juga ditentukan oleh gaya komunikasi dan pendekatan yang dilakukan oleh komunikator dan komunikan dalam menyampaikan pesan.

Proses komunikasi tersebut disebut dengan komunikasi dalam organisasi.

Komunikasi dalam organisasi secara sederhana dapat diartikan sebagai komunikasi antar sesama manusia (human communication) yang terjadi dalam konteks organisasi (Sendjaja, 1999: 133). Menurut Goldhaber, komunikasi dalam organisasi adalah "the process of creating and exchanging massages within a network of interdependent relationship to cope with environmental uncertainly" (Muhammad, 2005: 67). Dalam definisi ini terdapat 7 pokok pikiran, yaitu proses, pesan, jaringan, saling ketergantungan, hubungan, lingkungan dan ketidakpastian.

Untuk menghasilkan penciptaan dan saling tukar pesan di perpustakaan, maka harus diterapkan komunikasi organisasi yang baik. Komunikasi organisasi penting karena apabila komunikasi yang terjadi tidak baik, maka secara tidak langsung akan mempengaruhi iklim komunikasi yang akan memberikan dampak negatif terhadap keberlangsungan perpustakaan.

Komunikasi yang baik, secara tidak langsung dapat mempengaruhi cara hidup di sebuah organisasi (perpustakaan): kepada siapa orang-orang berbicara, siapa saja yang disukai, bagaimana perasaan masingmasing orang, bagaimana kegiatan kerja berlangsung dan bagaimana perkembangan orang-orang di dalam organisasi (Mulyana, 2006: 148). Komunikasi organisasi berpengaruh besar terhadap budaya organisasi di perpustakaan sehingga menjadi dasar dan tolak ukur dari keberhasilan manajemen perpustakaan.

Perpustakaan Proklamator Bung Hatta (PPBH) sebagai Perpustakaan Daerah Kota Bukittinggi saat ini sedang dalam proses transformasi menjadi UPT Perpustakaan Nasional. Keunggulan dari perpustakaan ini adalah sebagai perpustakaan kembar 
dengan Perpustakaan Proklamator Bung Karno di Blitar. PPBH Bukittinggi yang terletak di atas Bukit Gulai Bancah ini terdapat pemandangan yang indah dan didukung oleh arsitektur bangunan yang menarik dan dinding yang terbuat dari kaca, sehingga dapat memanjakan mata pengguna perpustakaan. Namun demikian hal tersebut tidak didukung dengan pelayanan, sarana, dan infrastruktur yang memadai.

Pustakawan juga mengalami krisis identitas sehubungan dengan proses transformasi perpustakaan dari UPT Dinas Pendidikan Nasional menjadi UPT Perpustakaan Nasional. Proses transformasi yang sudah berlangsung sejak akhir tahun 2006 mengalami pergeseran struktur organisasinya. Untuk sementara, selama proses transformasi masih berlangsung, PPBH Bukittinggi digabung dengan Kantor Arsip Bukittinggi dan Kantor Dokumentasi (KPAD) Kota Bukittinggi. KPAD ini langsung bertanggungjawab di bawah perintah Walikota Bukittinggi. Penggabungan ketiga bidang tersebut dan terletak dalam lokasi yang berbeda, menyebabkan sedikit kerancuan dalam struktur organisasi. Berikut adalah struktur organisasi PPBH Bukittinggi yang berada di bawah KPAD Kota Bukittinggi.

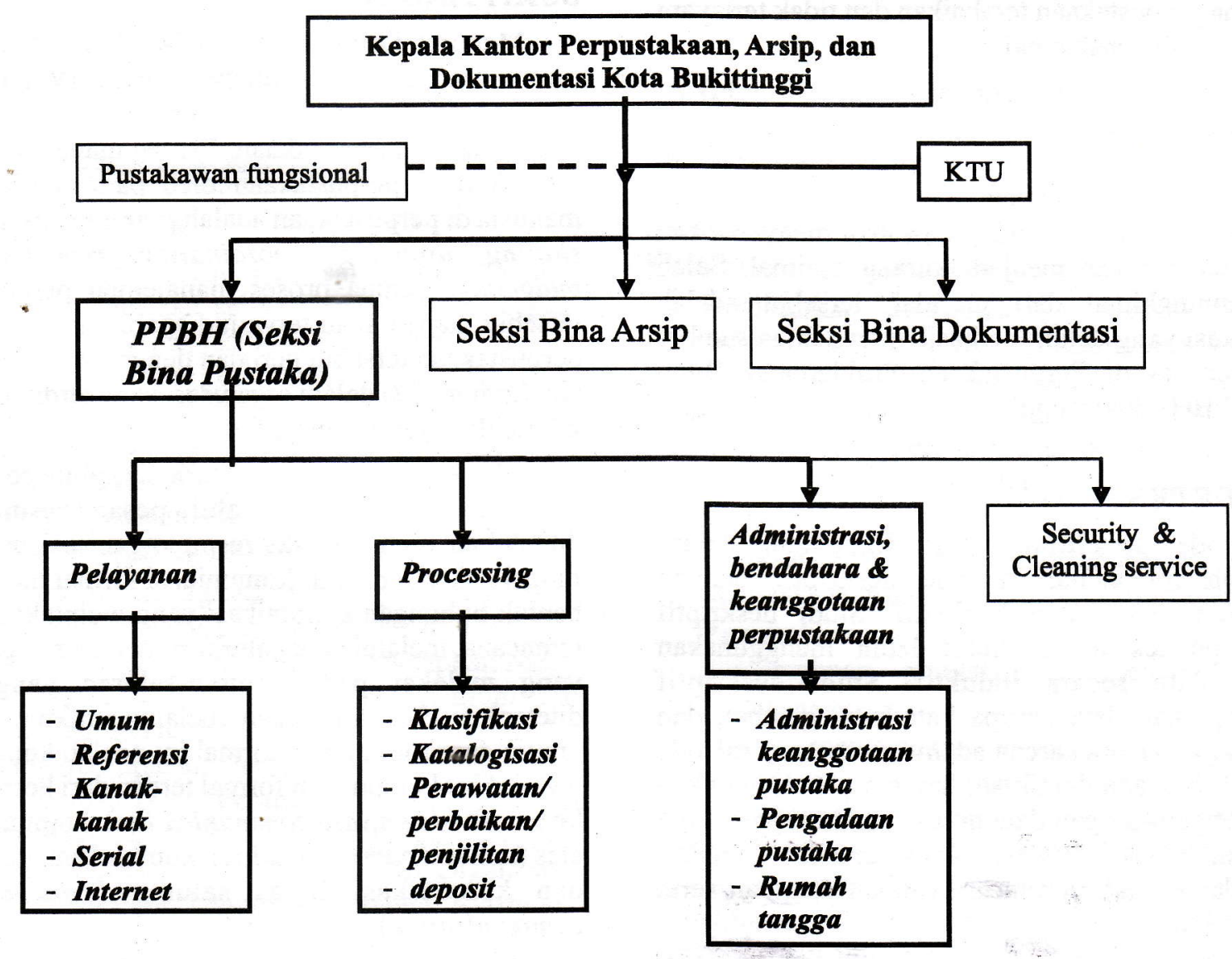

Gambar 1: Struktur Organisasi Perpustakaan Proklamator Bung Hatta (PPBH) Bukittinggi (sumber: Struktur Organisasi Kantor Perpustakaan, Arsip dan Dokumentasi

Kota Bukittinggi Perda No. 11 Tahun 2008) 
Struktur organisasi ini berpengaruh terhadap kinerja pustakawan karena adanya perubahan budaya organisasi. Setiap divisi di PPBH Bukittinggi belum melakukan pekerjaannya secara maksimal, seperti banyak pustakawan yang tidak tahu dan tidak mengerti harus mengerjakan pekerjaan apa. Mereka lebih pasrah dan menerima saja apa yang sudah ada, dan tidak berusaha berubah ke arah yang lebih baik. Hal ini menyebabkan beberapa pustakawan harus bekerja ganda. Rapat evaluasi kerja pustakawan juga jarang dilakukan. Selain itu pustakawan terlalu asik dengan sesama mereka, bahkan apabila ada pengguna yang ingin bertanya, mereka tidak tahu harus bertanya dimana dan kepada siapa. Hal tersebut menyebabkan pengguna perpustakaan terabaikan dan tidak terlayani dengan baik dan maksimal.

Belum dimanfaatkannya media komunikasi berbasis teknologi, perubahan budaya organisasi yang disebabkan oleh proses transformasi perpustakaan, rapat yang jarang dilakukan, dan kurangnya motivasi kerja dari pimpinan terhadap bawahan menyebabkan kinerja pustakawan menjadi kurang optimal. Salah satu kemungkinan dari masalah tersebut adalah komunikasi yang belum berhasil antar semua sumber daya manusia di Perpustakaan Proklamator Bung Hatta (PPBH) Bukittinggi.

\section{METODE PENELITIAN}

Metode penelitian yang digunakan dalam penelitian ini adalah metode deskriptif dengan melakukan pendekatan kualitatif. Studi deskriptif dengan pendekatan kualitatif lebih menggunakan analisis data secara induktif. Studi deskriptif mengumpulkan data berupa kata-kata, gambar, dan bukan angka-angka karena adanya penerapan metode kualitatif. Dengan demikian, laporan penelitian akan berisi kutipan-kutipan data untuk memberi gambaran penyajian laporan tersebut. Data tersebut mungkin berasal dari naskah wawancara, catatan lapangan, serta dokumen lainnya.

Teknik pengumpulan data merupakan langkah yang paling strategis dalam penelitian, karena tujuan utama dari penelitian adalah mendapatkan data. Tanpa mengetahui teknik pengumpulan data, peneliti tidak akan mendapatkan data yang memenuhi standar data yang ditetapkan. Teknik yang digunakan untuk mengumpulkan data penelitian adalah dengan observasi di Perpustakaan Proklamator Bung Hatta (PPBH) Bukittinggi, wawancara, serta studi pustaka dan analisis dokumen yang berkaitan dengan teori.
Sumber data atau informan dalam wawancara ini adalah: Kepala Perpustakaan, Arsip dan Dokumentasi; Kepala Seksi Bina Pustaka Perpustakaan Proklamator Bung Hatta Bukittinggi; Kepala Bagian Pelayanan; Kepala Bagian Processing; Kepala Bagian Administrasi, Bendahara dan Keanggotaan Perpustakaan; dan para staf Perpustakaan Proklamator Bung Hatta (PPBH) Bukittinggi. Waktu penelitian dan penulisan laporan adalah selama bulan FebruariDesember 2010.

\section{ALUR KOMUNIKASI DI PERPUSTAKAAN PROKLAMATOR BUNG HATTA (PPBH) BUKITTINGGI}

Menurut Luther Gulict dalam buku "Pengantar Ilmu Perpustakaan" (Sulistyo, 1993: 191) terdapat tujuh proses manajemen. Proses tersebut juga diterapkan di perpustakaan. Proses manajemen yang dilakukan di perpustakaan oleh para sumber daya manusia di perpustakaan adalah planning, organizing, staffing, directing, coordinating, reporting, dan budgeting. Semua proses manajemen perpustakaan tersebut, hanya akan terwujud apabila komunikasi di perpustakaan tersebut berjalan dengan baik. Terutama alur komunikasi dalam organisasi yang terdiri dari alur komunikasi formal dan informal.

Alur komunikasi formal terjadi apabila pesan atau informasi mengalir melalui pesan resmi yang ditentukan oleh hierarki resmi organisasi atau oleh fungsi pekerjaan. Alur komunikasi formal merupakan bentuk hubungan komunikasi yang diciptakan secara terencana, melalui jalur-jalur formal dalam organisasi, yang melekat pada saluran-saluran yang telah ditetapkan dan ditunjukan melalui struktur. Bentuk umum dari komunikasi formal ini adalah komunikasi tugas. Alur komunikasi formal terdiri dari komunikasi ke bawah (downward communication), komunikasi ke atas (upward communication), komunikasi horizontal, dan komunikasi lintas saluran (cross-channel communication).

Alur komunikasi informal terjadi jika sumber daya manusia perpustakaan berkomunikasi dengan yang lainnya tanpa memperhatikan posisi mereka dalam organisasi, sehingga arus komunikasi tersebut bersifat pribadi. Alur komunikasi informal terjadi di luar struktur, biasanya melalui saluran-saluran yang bersifat incidental, menurut kebutuhan atau hubungan interpersonal yang baik, atau atas dasar kesamaan kepentingan, hobi, dan lain-lain. Alur komunikasi informal disebut dengan desas-desus/selentingan. 
Berikut adalah kerangka pemikiran yang peneliti rancang:

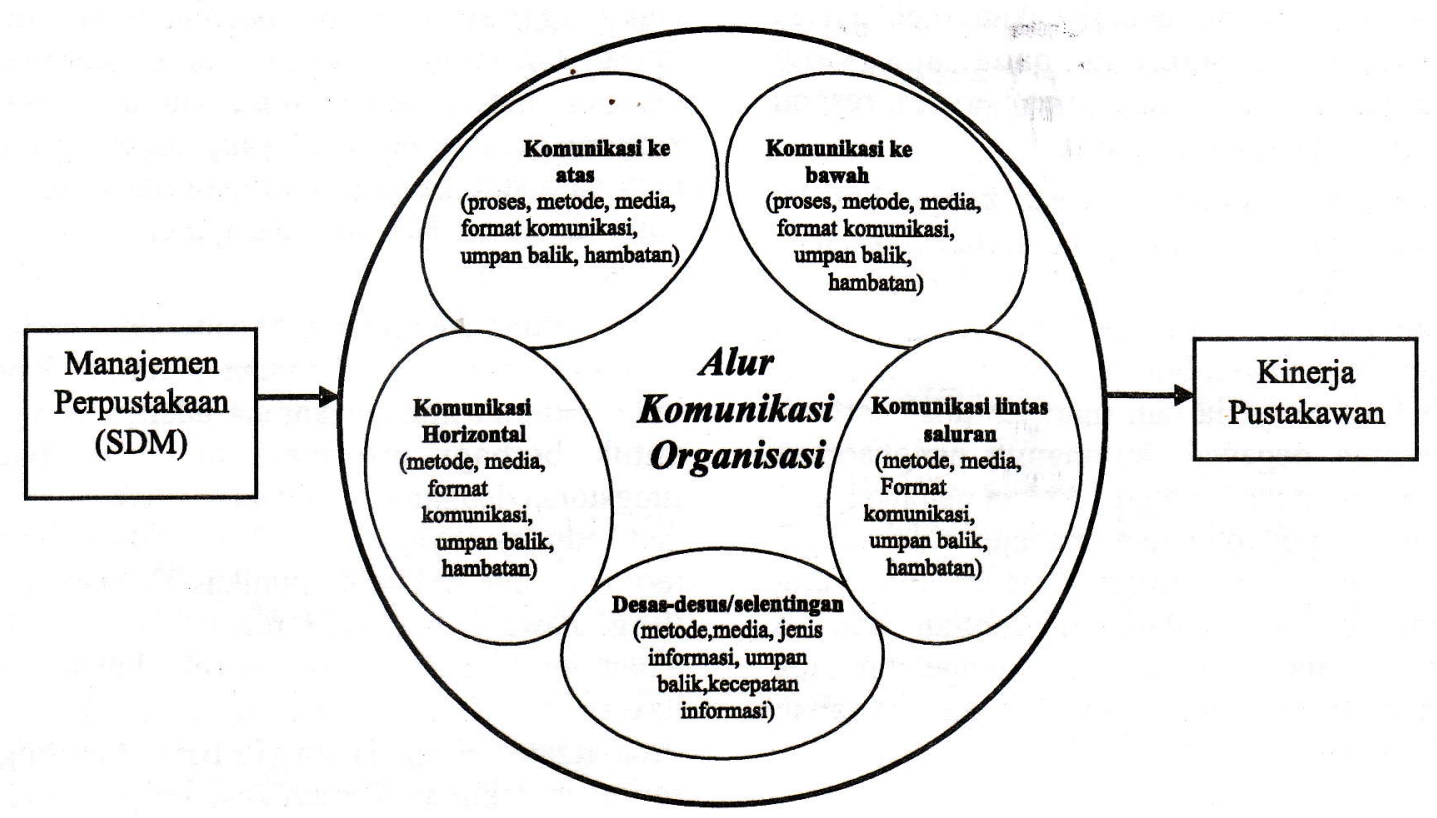

Gambar 2: Kerangka pemikiran

Alurkomunikasi dalam organisasi yang berjalan dengan efektif akan mampu mendorong prestasi kerja yang lebih baik. Sumber daya manusia di perpustakaan akan mengerti pekerjaan mereka secara lebih baik dan merasa lebih terlibat di dalam pekerjaan tersebut. $\mathrm{Hal}$ ini berarti bahwa dengan alur komunikasi organisasi yang baik, diharapkan kinerja pustakawan juga akan meningkat, sehingga manajemen perpustakaan juga berjalan dengan optimal. Dalam hal ini, alur komunikasi organisasi merupakan jembatan yang menghubungkan antara manajemen perpustakaan (SDM) dengan kinerja pustakawan.

Berikut ini akan dijelaskan mengenai jenis-jenis alur komunikasi yang sudah disinggung sebelumnya, mulai dari komunikasi ke bawah (downward communication), komunikasi ke atas (upward communication), komunikasi horizontal, komunikasi lintas saluran (cross-channel communication), dan komunikasi informal/selentingan/desas-desus. Sekaligus akan dijelaskan mengenai alur komunikasi yang terjadi di Perpustakaan Proklamator Bung Hatta (PPBH) Bukittinggi.

Hal pertama adalah mengenai komunikasi ke bawah (downward communication). Terdapat lima hal yang biasanya disampaikan oleh atasan kepada bawahan dalam berkomunikasi, yaitu: informasi mengenai instruksi tugas; informasi mengenai rasionalitas pekerjaan, mengapa suatu tugas harus dilaksanakan; informasi tentang karakteristik ideologi pekerjaan sebagai misi perusahaan guna memperkuat loyalitas, moral, dan motivasi; informasi mengenai kebijakan, peraturan-peraturan yang berlaku, dan praktek-praktek organisasi; dan umpan balik/respon kepada para bawahan mengenai kinerja pustakawan dan memberikan motivasi kepada pustakawan.

Berdasarkan hasil penelitian mengenai komunikasi ke bawah di Perpustakaan Proklamator Bung Hatta (PPBH) Bukittinggi, maka dapat diketahui bahwa komunikasi ke bawah tidak berjalan lancar dan tidak sesuai dengan teori komunikasi ke bawah. Komunikasi ke bawah yang lancar seharusnya menggunakan aliran informasi berdasarkan struktur organisasi perpustakaan terutama bagi proses aliran informasi berurutan. Yang terjadi di PPBH Bukittinggi adalah atasan jarang memperhatikan struktur organisasi dalam berkomunikasi dengan bawahan. Kemudian metode yang digunakan seharusnya seimbang antara metode lisan, tulisan dan campuran, tetapi yang terjadi di perpustakaan ini lebih sering menggunakan metode lisan. Atasan di PPBH Bukittinggi juga kurang memanfaatkan media komunikasi yang ada dalam memberikan informasi kepada bawahannya, mereka lebih mengandalkan format komunikasi interpersonal secara tatap muka. Padahal atasan bisa lebih memanfaatkan berbagai media (seperti media rapat, telepon, disposisi, email, dan laim-lain) dan sering menggunakan format komunikasi kelompok kecil agar lebih efektif dan 
menghemat waktu. Untuk umpan balik dari bawahan terhadap pesan yang dikomunikasikan oleh atasan beraneka ragam tergantung pada apa yang dikomunikasikan, tetapi yang memberikan respon terbatas hanya pada beberapa orang.

Bahasan kedua adalah mengenai komunikasi ke atas (upward communication). Komunikasi ke atas biasanya mengalami berbagai kendala. Kendala yang umum terjadi antara lain karena: kecenderungan bagi pegawai untuk menyembunyikan pikiran mereka; perasaan bahwa penyelia dan manajer tidak tertarik kepada masalah pegawai; kurangnya penghargaan bagi komunikasi ke atas yang dilakukan pegawai; dan perasaan bahwa penyelia dan manajer tidak dapat dihubungi dan tidak tanggap pada apa yang disampaikan pegawai. Padahal dengan adanya komunikasi ke atas, atasan lebih mengetahui apa sebenarnya yang diinginkan dan dirasakan bawahan dalam melakukan pekerjaannya dan untuk kemajuan organisasi itu sendiri.

Komunikasi ke atas di Perpustakaan Proklamator Bung Hatta (PPBH) Bukittinggi tidak berjalan dengan lancar dan tidak sesuai dengan teori komunikasi ke atas. Hal ini terlihat dari kendala-kendala yang sudah peneliti sebutkan sebelumnya terbukti setelah mendalami faktor-faktor yang mendukung komunikasi ke atas, seperti proses aliran komunikasi, metode yang digunakan, media yang dipakai, format komunikasi, serta umpan balik dalam berkomunikasi. Selain itu, jumlah staf yang melakukan komunikasi ke atas hanya beberapa orang. Sebagian besar staf PPBH Bukittinggi cenderung menyembunyikan pikiran mereka. Staf yang sering mengungkapkan masalahnya merasa bahwa atasannya tidak tertarik dengan masalah mereka karena atasan jarang memberikan respon terhadap masalah staf. Walaupun merespon, kadang atasan tidak bisa memberikan penyelesaian dan tidak tanggap atas masalah stafnya. Hal ini menyebabkan staf menganggap bahwa komunikasi ke atas tidak begitu penting.

Ketiga, komunikasi horizontal yang dilakukan oleh sesama rekan kerja dalam unit kerja yang sama dan dengan kedudukan yang sama. Tujuan melakukan komunikasi horizontal, yaitu: 1.) Untuk mengkoordinasi penugasan kerja, 2.) Saling berbagi informasi mengenai rencana dan kegiatan, 3.) Untuk memecahkan masalah, 4.) Untuk memperoleh pemahaman bersama, 5.) Untuk mendamaikan, berunding, dan menengahi perbedaan, dan 6.) Untuk menumbuhkan dukungan antarpersonal.

Komunikasi horizontal yang terjadi di
Perpustakaan Proklamator Bung Hatta (PPBH) Bukittinggi sudah sesuai dengan teori dan berjalan lancar. Penggunaan metode komunikasi yang tepat, dengan media yang tepat juga, serta format komunikasi interpersonal yang memang dibutuhkan oleh para staf. Selain itu umpan balik atas informasi yang dikemukakan di antara mereka juga berjalan dengan lancar.

Bahasan keempat mengenai komunikasi lintas saluran (cross-channel communication). Komunikasi lintas saluran muncul karena adanya keinginan staf untuk berbagi informasi melewati batas-batas fungsional dengan staf lain yang tidak memiliki posisi dan kedudukan yang sama. Komunikasi lintas saluran terjadi karena staf berkomunikasi dengan orang-orang yang diawasi dan yang mengawasi mereka, tetapi dalam struktur organisasi, mereka bukan atasan atau bawahan mereka. Biasanya di Perpustakaan Proklamator Bung Hatta (PPBH) Bukittinggi, yang sering melakukan komunikasi lintas saluran adalah Staf Kantor Tata Usaha yang memegang SK Pegawai dengan para staf bagian lain. Komunikasi lintas saluran yang terjadi di PPBH Bukittinggi mencakup faktor-faktor metode komunikasi, media yang digunakan, format komunikasi, dan umpan balik dari penerima pesan/informasi.

Ada dua syarat sehingga komunikasi lintas saluran bisa dilaksanakan, yaitu setiap staf yang ingin melakukan komunikasi lintas saluran harus meminta izin terlebih dahulu kepada atasannya dan setiap staf yang terlibat dalam komunikasi lintas saluran harus memberitahukan hasil-hasil pertemuanya kepada atasannya. Tetapi di PPBH Bukittinggi, memperlihatkan bahwa para staf mengabaikan dua syarat di atas. Mereka cenderung tidak meminta izin kepada atasannya dan langsung melakukan komunikasi lintas saluran. Hal ini dapat terlihat pada beberapa bawahan tingkat bawah yang langsung berkomunikasi dengan tingkatan manajemen puncak ataupun. Bisa dikatakan mereka melangkahi penyelia/atasan langsung mereka. Mereka juga jarang yang melaporkan kembali kepada atasan langsung mereka (di dalam struktur organisasi) mengenai apa saja yang dibicarakan. Hal ini membuktikan bahwa komunikasi lintas saluran di PPBH Bukittinggi tidak berjalan lancar dan tidak sesuai dengan teori komunikasi lintas saluran.

Terakhir mengenai komunikasi informal/ selentingan/desas-desus. Alur komunikasi ini merupakan jenis komunikasi yang terjadi secara spontan, tidak direncanakan, dan tanpa memikirkan 
kedudukan sumber informasi dan penerima informasi. Jenis komunikasi ini sering juga disebut sebagai gosip. Komunikasi informal/selentingan/desas-desus. yang terjadi sudah sesuai dengan teori dan sudah berjalan dengan lancar. Hal ini ditandai dengan berlakunya sifat-sifat selentingan/desas-desus menurut W. L. Davis dan O'Connor, seperti selentingan/desas-desus yang tersebar dari mulut ke mulut dalam jangka waktu yang cepat. Penyebaran informasi juga tidak memperhatikan struktur organisasi PPBH Bukittinggi. Walaupun bentuk pesan yang disampaikan berupa selentingan/desas-desus, pesan tersebut kira-kira sebesar $85 \%$ adalah cermat dan benar. Para pelaku komunikasi informal lebih menganggap bahwa $15 \%$ pesan yang tidak cermatlah yang penting. Hal ini menimbulkan interpretasi yang salah di lingkungan pustakawan PPBH yang melakukan komunikasi informal.

Selanjutnya, kendala/hambatan berkomunikasi di PPBH Bukittinggi terjadi karena lima faktor penting yang mempengaruhinya. Kelima faktor penting ini adalah:

1. Belumh terealisasinya PPBH Bukittinggi menjadi UPT Perpustakaan Nasional Republik Indonesia. Masalah ini menjadi masalah utama karena berpengaruh terhadap berbagai aspek organisasi. Proses pemindahan status ini terjadi sangat lama karena adanya tarik ulur oleh Pemerintah Daerah Kota Bukittinggi dengan Kementerian Negara Pendayagunaan Aparatur Negara dan Reformasi Birokrasi.

2. Peraturan Daerah Nomor 11 Tahun 2008 tentang Susunan Organisasi dan Tata Kerja Kantor Perpustakaan, Arsip dan Dokumentasi Kota Bukittinggi. Dalam peraturan daerah ini, PPBH Bukittinggi tidak lagi berdiri sendiri, tetapi menjadi bagian dari Kantor Perpustakaan, Arsip dan Dokumentasi. PPBH Bukittinggi berubah menjadi Seksi Bina Pustaka, sehingga terjadi pegeseran pada tujuan, visi, dan misi PPBH Bukittinggi.

3. Penempatan staf yang tidak tepat, rangkap jabatan dan kurangnya sumber daya manusia di PPBH Bukittinggi juga menjadi masalah yang mengganggu lancarnya komunikasi di PPBH Bukittinggi sehingga berpengaruh terhadap kinerja SDM.

4. Kurangnya motivasi dari atasan di PPBH Bukittinggi menjadikan staf kurang loyal terhadap pekerjaannya.
5. Dana yang kurang berpengaruh pada pola kerja staf di PPBH Bukittinggi, bisa menghambat pekerjaan para staf. Sehingga menimbulkan iklim komunikasi organisasi yang tidak baik diantara staf dan atasannya.

\section{PENUTUP}

Kesimpulan yang peneliti peroleh setelah melakukan penelitian di Perpustakaan Proklamator Bung Hatta (PPBH) Bukittinggi adalah:

1. Komunikasi ke bawah (Downward Communication) yang terjadi di lingkungan pustakawan PPBH Bukittinggi tidak berjalan dengan lancar dan kurang sesuai dengan teori komunikasi ke bawah dalam sebuah organisasi.

2. Komunikasi ke atas (Upward Communication) yang terjadi di PPBH Bukittinggi tidak berjalan lancar dan tidak sesuai dengan teori komunikasi ke atas di dalam organisasi.

3. Komunikasi horizontal yang terjadi di PPBH Bukittinggi menggunakan metode lisan dengan format komunikasi interpersonal karena mereka berada dalam satu ruangan yang sama dan lebih efektif bagi staf untuk tidak menggunakan media apapun. Komunikasi horizontal di PPBH Bukittinggi sudah berjalan dengan lancar dan sesuai dengan teori komunikasi horizontal dalam organisasi.

4. Komunikasi lintas saluran (cross-channel communication) di PPBH Bukittinggi tidak berjalan dengan lancar dan tidak sesuai dengan teori komunikasi lintas saluran dalam suatu organisasi karena komunikasi sering dilakukan tanpa persetujuan dari penyelia/atasannya dan sering melanggar struktur organisasi perpustakaan.

5. Komunikasi informal/selentingan/desas-desus yang terjadi di PPBH Bukittinggi berlangsung dengan lancar dan sesuai dengan teori komunikasi informasi/selentingan/desas-desus dalam organisasi.

Saran dan masukan untuk mengurangi kendala/hambatan yang ditemukan dalam alur komunikasi organisasi di Perpustakaan Proklamator Bung Hatta (PPBH) Bukittinggi, antara lain:

1. Setiap pelaku organisasi di lingkungan pustakawan PPBH Bukittinggi harus meningkatkan kemampuannya dalam berkomunikasi agar tercipta suasana kerja yang 
kondusif dan kinerja yang diinginkan dari staf perpustakaan ini.

2. Pemerintah Daerah Kota Bukittinggi dan pejabat KPAD ikut membantu dalam mempercepat proses peng-UPT-an PPBH Bukittinggi agar tidak terjadi kesimpangsiuran yang mengganggu kinerja staf.

3. Pemerintah Daerah Kota Bukittinggi harus membuat peraturan daerah yang sifatnya lebih mendukung terhadap kemajuan PPBH Bukittinggi.

4. Perpustakaan harus menambah sumber daya manusia (SDM) yang kompeten di Bidang Ilmu Perpustakaan dan harus cermat dalam menempatkan staf. Hal ini berguna agar tidak terjadi lagi kekurangan sumber daya manusia, rangkap jabatan, dan staf bisa bekerja sesuai dengan kompetensinya masing-masing.

5. Pemimpin/atasan harus aktif memberikan motivasi yang membangun kepada staf PPBH Bukittinggi, bukan hanya informasi yang bersifat instruksi. Hal ini berguna agar staf bekerja lebih giat sehingga kinerja organisasi menjadi lebih baik.

\section{DAFTAR PUSTAKA}

Bryson, Jo, Managing Information Services: an integrated approach, Gowel, Montpelier, VT, 1997.

Bungin, Burhan, Penelitian Kualitatif: Komunikasi, Ekonomi, Kebijakan Publik, dan Ilmu Sosial Lainnya, Kencana, Jakarta, 2009.

Curtis, Dan B., Floyd, James J., dan Winsor, Jerry L., Komunikasi Bisnis dan Profeional, Remaja Rosdakarya, Bandung, 1999.

Effendy, Onong Uchjana, Ilmu Komunikasi: Teori dan Praktek, Remaja Rosdakarya, Bandung, 2003.

Evans, G. Edward dan Ward, Patricia Layzell, Management Basics for Information Professionals, ed. 2, Neal-Schuman, New York, NY, 2007.

Fathoni, Abdurrahmat, Organisasi dan Manajemen Sumber Daya Manusia, Rineka Cipta, Jakarta, 2006.

Gorman dan Clayton, Peter, Qualitative Research for the Information Professional: a practical handbook, Library Association, London, 1997.

Griffin, Emory A., A First Look at Communication Theory, ed. 5, McGraw-Hill, Boston, 2003.
Jablin, Fredric M., dan Putnam, Linda L., The New Handbook of organizational communication: advances in Theoty, Research, and Methods, Sage, Sacramento, CA, 2000.

Lasa H. S., Manajemen Perpustakaan, Gama Media, Yogyakarta, 2005.

Littlejohn, Stephen W., Theories of Human Communication, ed. 5, Wadsworth Publishing, Belmont, 1996.

Moleong, Lexy J., Metodologi Penelitian Kualitatif, Remaja Rosdakarya, Bandung, 2007.

Muchlas, Makmuri, Perilaku Organisasi, Gadjah Mada University Press, Yogyakarta, 2005.

Muhammad, Arni, Komunikasi Organisasi, Bumi Aksara, Jakarta, 2005.

Mulyana, Deddy, Ilmu Komunikasi: Suatu Pengantar, Remaja Rosdakarya, Bandung, 2004.

(editor), Komunikasi Organisasi: Strategi Meningkatkan Kinerja Perusahaan, R. Wayne Pace dan Don F. Faules (penulis), Remaja Rosdakarya, Bandung, 2006.

Nasution, S., Metode Penelitian NaturalistikKualitatif, Tarsito, Bandung, 2002.

Pendit, Putu Laxman, Penelitian Ilmu Perpustakaan dan Informasi: Suatu Diskusi Epistemologi dan Metodolagi, JIP-FSUI, Jakarta, 2003.

Rakhmat, Djalaluddin, Metode Penelitian Komuniasi: Dilengkapi Contoh Analisis Statistik, Remaja Rosdakarya, Bandung, 2005.

Soehartono, Irawan, Metode Penelitian Sosial : Suatu Teknik Penelitian Bidang Kesejahteraan Sosial dan Ilmu Sosial Lainnya, Remaja Rosdakarya, Bandung, 2004.

Sendjaja, S. Djuarsa, Teori Komunikasi, Universitas Terbuka, DEPDIKBUD, Jakarta, 1999.

Stueart, Robert D. dan Moran, Barbara B., Library and Information Center Management, ed. 4, Libraries Unlimited, Denver, CO, 1993.

Sugiyono, Memahami Penelitian Kualitatif: Dilengkapi contoh proposal dan laporan penelitian, Alfabeto, Bandung, 2007.

Sulistyo, Basuki, Pengantar Ilmu Perpustakaan, Gramedia Pustaka Utama, Jakarta,1991.

Treece, Malra, Communication for Business and the Professions, ed. 4, Allyn and Bacon, Boston, MA, 1989. 
Umstot, Denis, D., Understanding Organizational Behavior, West Publishing, New York, NY, 1987.

Usmara (editor), Handbook of Organizations: Kajian dan Teori Organisasi, Edward E. Lawler III, John P. Kotter, dkk. (penulis), Amara Books, Jogjakarta, 2003.
Wibisono, Dermawan, Manajemen Kinerja: Konsep, Desain, dan Teknik Meningkatkan Daya Saing Perusahaan, Erlangga, Jakarta, 2006.

Winardi, J., Manajemen Perilaku Organisasi, Edisi revisi, Kencana, Jakarta, 2007. 